\title{
Morphological, Cultural and Pathological Variation of Alternaria alternata causing Leaf Spot of Niger
}

\author{
Archana W. Shingne*, Ashwini R. Bagade, Punam N. Usendi and G. K. Giri \\ Department of Plant Pathology, Dr.Panjabrao Deshmukh Krishi Vidyapeeth, \\ Akola- (M.S.), India \\ *Corresponding author
}

\section{A B S T R A C T}

\begin{tabular}{l} 
K e y w o r d s \\
$\begin{array}{l}\text { Alternaria } \\
\text { alternata, Niger, } \\
\text { Guizotia abyssinica, } \\
\text { Leaf spot, Cultural } \\
\text { and Morphological } \\
\text { characterization }\end{array}$ \\
\hline Article Info \\
$\begin{array}{l}\text { Accepted: } \\
\text { 24 August } 2020 \\
\text { Available Online: } \\
\text { 10 September } 2020\end{array}$ \\
\hline
\end{tabular}

Leaf spot disease (Alternaria alternata) causes severe foliar damage to niger crop. The isolates of A.alternata were collected from different location and tested for their variability in term of morphological, cultural and pathological variation viz., growth rate, colony colour, aerial mycelium colour, growth pattern, sporulation, conidial size, conidial sepation. In case of growth rate $\mathrm{Aa} 1$ and $\mathrm{Aa} 2$ was observed very fast growing it cover 70$73 \mathrm{~mm}$ growth within 7 days of inoculation on PDA media. Among the five isolates different colony colour and aerial mycelium colour was observed. The variation in mycelial growth pattern was observed in Aa2 isolate growing with circular pattern and other four show irregular growth pattern. In respect of sporulation abundant sporulation was observed in Aa2 show more than 30 spore in single microscopic field. In case of conidial size maximum conidial length (41.10) was noticed in Aa5 and breadth (11.66) in Aa1. The Maximum number of transverse septa were observed in Aa5 (4-8) and longitudinal septa in Aa1 and Aa2 (0-3). In case of pathogenicity Aa2 isolates was most virulent than other isolates of Alteranria alternata.

\section{Introduction}

Niger [Guizotia abyssinica, family: compositae] is commonly known as ramtil. It is an annual dicotyledonous herb Plant erect, stout and branched type, flowers are yellow, slightly green and two to three capitulates grow together. It is cross pollinated and minor, traditional oil seed crop in India. It is important minor, edible, traditional oil seed crop in India. It is mainly cultivated in tribal pockets of Gujarat, M.P, Orissa, Maharashtra, Bihar, Karnataka and Andhra Pradesh in India
(Gupta, 2018). India ranks first in area, production and export of niger in the world (Rai et al., 2016). It provides about 3 per cent of the edible oil requirement of the country (Getinet and Sharma, 1996). Niger contains $34-36 \%$ quality oil with $18-20 \%$ protein in the seed (Rai et al., 2016).

Niger oil has good keeping quality and has < $70 \%$ unsaturated fatty acids free from toxin. linoleic acid $45-66 \%$, oleic acid $13-39 \%$ and palmitic acid 8.2-9.6\%.It has good potential for soil conservation, land rehabilitation and 
as a biofertilizer. These attributes favour its cultivation on hilly areas, marginal and submarginal lands in and around the forest (Ranganatha et al., 2009). Nigeris suffering from various fungal disease among them Alternaria leaf spot is distributed throughout the Niger growing areas of India. Leaf blight of niger caused by Alternaria alternata is considered to be a major devastating disease to the Niger in India and also reduce the yield and oil quality (Nagaraja and Krishnappa 2016).

The disease is favoured by warm and humid climate. The accidental rain at flowering stage leads the expansion of alternaria leaf spot incidence and results in the poor seed set and seed yield (Sandipan et al., 2014). Diseases cause heavy damage upto 35-40 per cent to this crop and reduce its seed yields upto 20-30 per cent.

\section{Materials and Methods}

\section{Isolation and Identification of A. alternata}

The present investigation on morphological and cultural variability among the isolates of Alternaria alternata was conducted at the Department of Plant Pathology, Post Graduate Institute, Dr. Panjabrao Deshmukh Krishi Vidyapeeth (Dr. PDKV), Akola. In order to isolate pathogen infected leaf sample were cut along with healthy leaf and surface sterilized with $0.1 \%$ sodium hypochlorite solution for one minute and washing with three times by sterilized distilled water. The bits were placed in petriplates containg PDA medium. The plates were incubated at $27 \pm 2{ }^{0} \mathrm{C}$ for 7 days. All the above operations were carried out in sterilized condition (under laminar air flow unit). The isolated fungi were identified as Alternaria alternata on the basis of morphological characters and published literature. The fungal culture was purified by following hyphal tip method and culture obtained was maintained on potato dextrose agar (PDA) medium slants by adopting subsequent sub culturing at, regular intervals.

\section{Morphological and culturalcharacteristics}

The growth characters of different isolates of Alternaria alternata were studied on PDA media morphological characters viz., mycelium growth ratecultural characters viz., colony colour, aerial mycelium colour, growth pattern, sporulation, size of conidia, and septation of conidia.

\section{Pathogenicity test}

Three weeks old healthy niger seedling were selected for inoculation selected seedlings surface disinfect with sodium hypochloride for two minutes and then with water. Conidial suspension was prepared which having $(1 \times 10$ ${ }^{6}$ spore/ml). The selected seedling first injured with carborandom powder then were inoculated with conidial suspension with the help of hand sprayer.

After inoculation the inoculated crop were placed in green house, where realtive humidity $80-90 \%$ and optimum temperature $\left(27 \pm 1^{\circ} \mathrm{c}\right)$ maintained for further development of symptoms of alternaria leaf spot. Initiation of typical symptoms after 6-8 days on the healthy leaf was observed. The diseased portion cut into small pieces along with healthy part and the pathogen was reisolated on the PDA medium from the inoculated plants for confirmation of Koch's postulates.

\section{Results and Discussion}

Growth rate variability among the isolates Alternaria alternata

The isolates Aa2 and Aa1 was observed to be very fast growing it cover 70-74 $\mathrm{mm}$ mycelium growth within seven days of 
incubation. While isolates Aa5 and Aa4 are considered fast growing with mycelial growth $65-70 \mathrm{~mm} 7$ days of incubation.

The Aa3 isolates from Deulgaon Mahi (Buldhana) was slow growing with $61.5 \mathrm{~mm}$ growth within 7days. These results are in confirmity with the finding of Singh et al., (2014) who observed variation in radial mycelial growth of Alternaria helianthi on PDA. Ginoya and Gohel (2015) and Jankar et al., (2017) also recorded variation in mycelial growth of Alternaria alternata on different media. In the present investigation also the varied mycelial growth rate was recorded during three to seven days of incubation of $A$. alternata isolates obtained from leaf spot disease of niger.

Table.1 Location wise naming of isolates and growth rate of various isolates of Alternaria altenata on PDA

\begin{tabular}{|c|c|c|c|c|c|c|}
\hline \multirow{2}{*}{$\begin{array}{l}\text { Sr. } \\
\text { No. }\end{array}$} & \multirow[t]{2}{*}{ Location } & \multirow[t]{2}{*}{ Isolates } & \multicolumn{3}{|c|}{ Radial mycelial growth $(\mathbf{m m})^{*}$} & \multirow{2}{*}{$\begin{array}{c}\text { Mycelial } \\
\text { growth rate }\end{array}$} \\
\hline & & & $3^{\text {rd }}$ DAI & $5^{\text {th }}$ DAI & $7^{\text {th }}$ DAI & \\
\hline 1. & Sindakhed Raja & Aal & 26.50 & 51.00 & 70.00 & Very fast \\
\hline 2. & Chikhali & $\mathrm{Aa} 2$ & 29.50 & 54.00 & 73.00 & Very fast \\
\hline 3. & Deulgaon Mahi & Aa3 & 20.50 & 40.00 & 61.50 & Slow \\
\hline 4. & $\begin{array}{l}\text { Department of Plant Pathology } \\
\text { Dr. PDKV, Akola }\end{array}$ & $\mathrm{Aa} 4$ & 27.50 & 52.00 & 66.50 & Fast \\
\hline 5. & $\begin{array}{l}\text { Department of Agronomy Dr. } \\
\text { PDKV, Akola }\end{array}$ & Aa5 & 22.50 & 50.00 & 66.00 & Fast \\
\hline
\end{tabular}

DAI- Days after Inoculation

Table.2 Cultural characters of the test isolates of Alternaria alternate

\begin{tabular}{|c|c|c|c|c|}
\hline Isolates & Colony colour & $\begin{array}{c}\text { Aerial } \\
\text { mycelium colour }\end{array}$ & Growth pattern & $\begin{array}{c}\text { Sporulation } \\
\text { category }\end{array}$ \\
\hline Aa1 & Greyish black & Dull white & Irregular & 3 \\
\hline Aa2 & Blackish colour & Dark grey & Circular,Concentric & 4 \\
\hline Aa3 & Greenish brown & Light brown & Irregular & 2 \\
\hline Aa4 & Dark brown & Light brown & Irregular & 3 \\
\hline Aa5 & Blackish green & Dull white & Irregular & 3 \\
\hline
\end{tabular}

Categories of sporulation given by Ginoya and Gohel (2015) for Altenaria alternate

\begin{tabular}{|l|c|c|}
\hline \multicolumn{1}{|c|}{ Rate of sporulation } & No. of spore /microscopic field (45x) & Sporulation category \\
\hline Abundant & $>30$ & 4 \\
\hline Good & $20-30$ & 3 \\
\hline Moderate & $10-20$ & 2 \\
\hline Scanty & $<10$ & 1 \\
\hline Nil & 0 & 0 \\
\hline
\end{tabular}


Table.3 Size and sepatation of conidia of Alternaria alternata on PDA

\begin{tabular}{|c|c|c|c|c|}
\hline \multirow{2}{*}{ Isolates } & \multicolumn{2}{|c|}{ Size of conidia $(\boldsymbol{\mu m})$} & \multicolumn{2}{c|}{ Sepatation of conidia } \\
\cline { 2 - 5 } & Length & Breadth & Transverse & Longitudinal \\
\hline Aa1 & 21.75 & 11.62 & $1-4$ & $0-3$ \\
\hline Aa2 & 23.75 & 11.52 & $2-6$ & $0-3$ \\
\hline Aa3 & 37.75 & 10.87 & $3-7$ & $0-2$ \\
\hline Aa4 & 20.30 & 11.30 & $2-4$ & $0-2$ \\
\hline Aa5 & 41.10 & 10.20 & $4-8$ & $0-1$ \\
\hline
\end{tabular}

Table.4 Pathological variation in the isolates of Alternaria alternate

\begin{tabular}{|c|c|c|c|}
\hline Sr.No. & Isolates & $\begin{array}{c}\text { Days to initiate disease } \\
\text { symptoms }\end{array}$ & $\begin{array}{c}\text { Average No. of } \\
\text { lesions / plant }\end{array}$ \\
\hline $\mathbf{1 .}$ & $\mathrm{Aa} 1$ & 8 & 6 \\
\hline $\mathbf{2 .}$ & $\mathrm{Aa} 2$ & 6 & 8 \\
\hline $\mathbf{3 .}$ & $\mathrm{Aa} 3$ & 10 & 4 \\
\hline $\mathbf{4 .}$ & $\mathrm{Aa} 4$ & 9 & 4 \\
\hline $\mathbf{5 .}$ & $\mathrm{Aa} 5$ & 12 & 3 \\
\hline
\end{tabular}

Fig.1 Growth of Alternaria alternata isolates on PDA and conidia

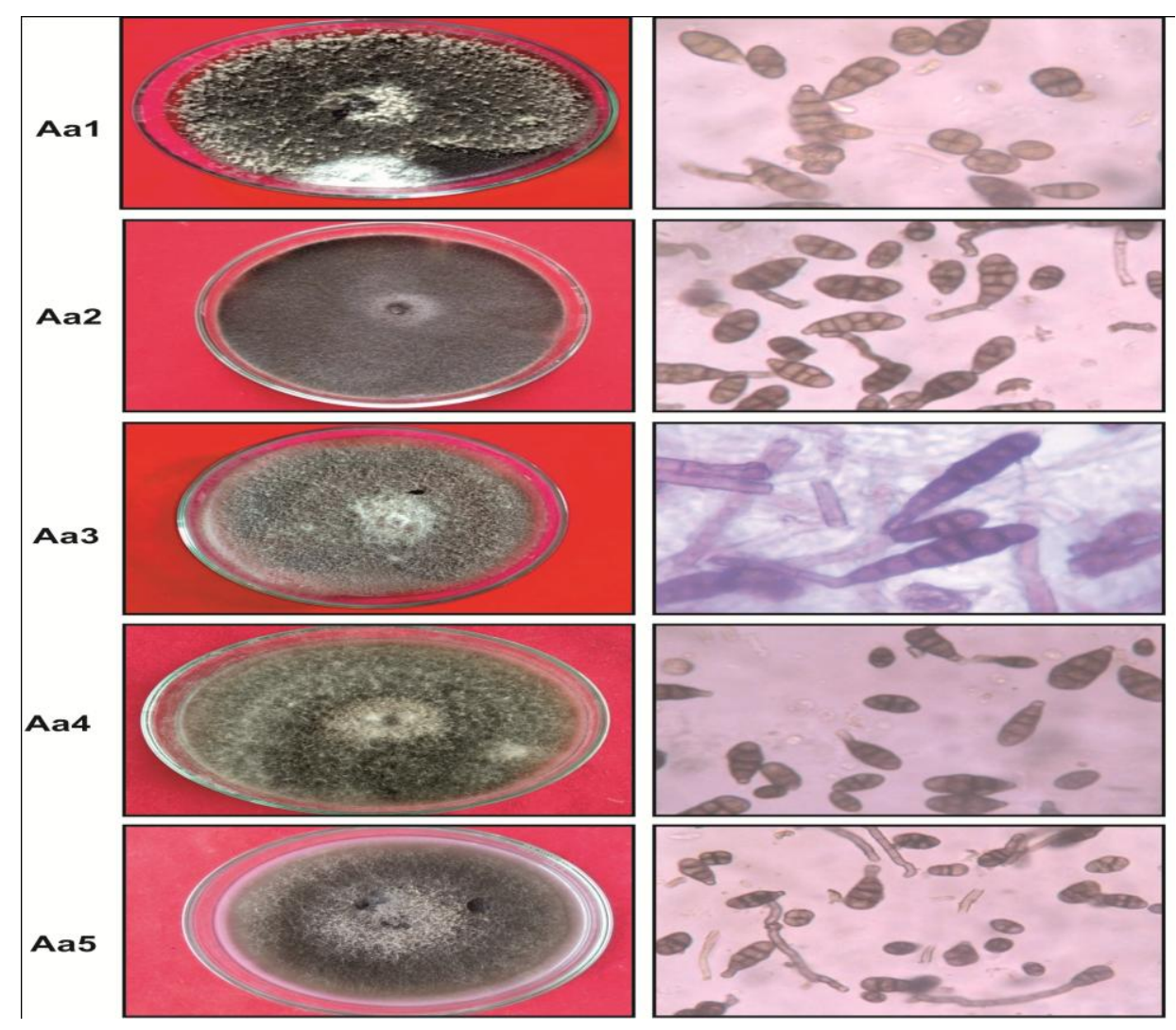


Fig.2 Pathogenicity test of Alternaria alternata

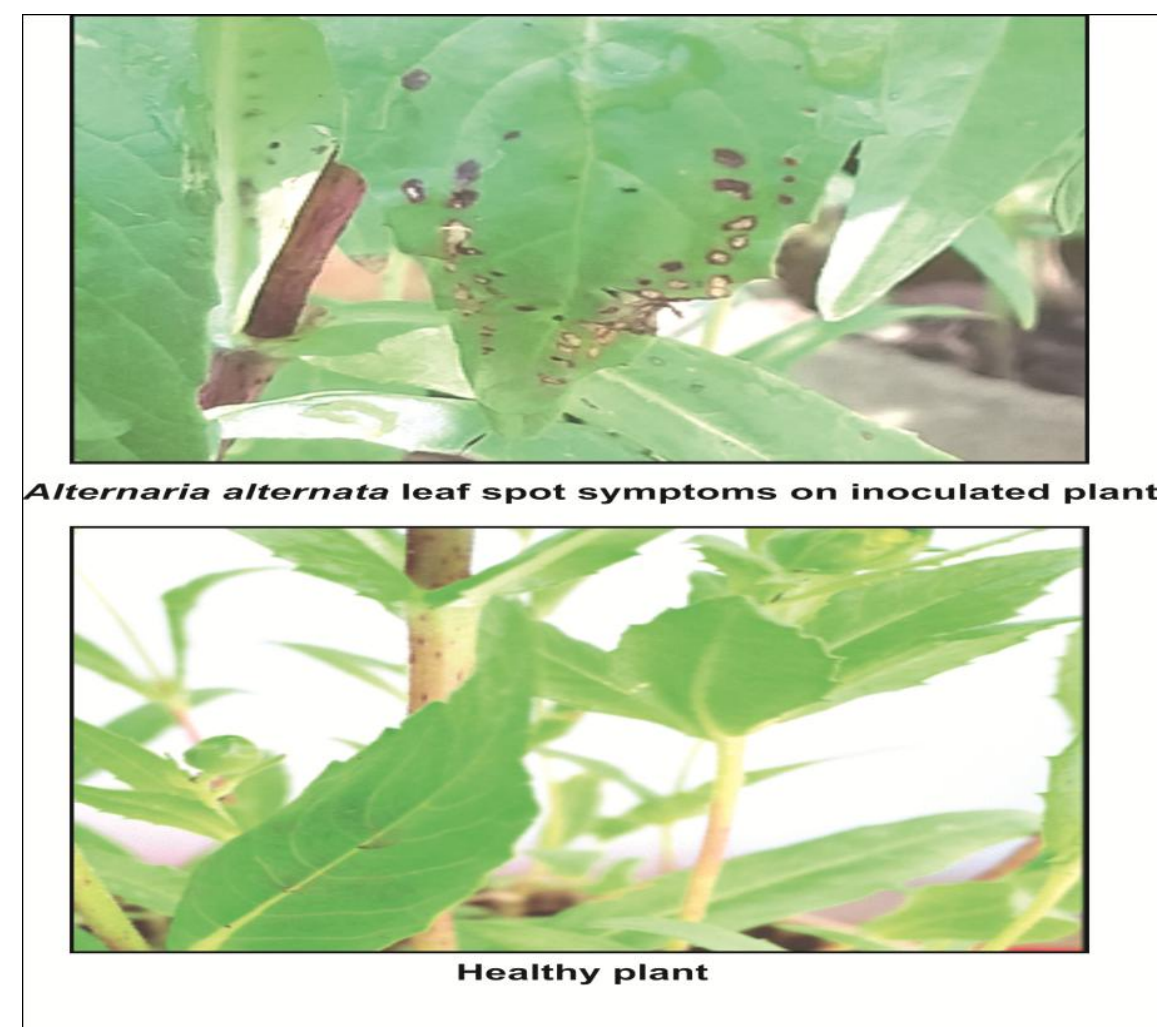

Cultural characters of the test isolates of Alternaria alternata

The result is given in table 2 . revealed that there was a considerable variation among colony colour on PDA medium. Among the different isolates greyish black colour was observed in Aal isolate. However Black colour in $\mathrm{Aa} 2$, greenish brown colour in Aa3, dark brown in Aa4 and greenish black colour in Aa5 isolates after seven days of incubation on PDA. The isolates Aa1 and Aa5 showed dull white colour of aerial mycelium on PDA. Similarly Aa3, Aa4 showed light brown and Aa2 showed dark grey colour. The variation in mycelial growth patterns among various isolates were also observed $\mathrm{Aa} 2$ growing with circular pattern of margin and Aa1, Aa3, Aa4 and Aa5 isolates were growing with irregular pattern of margin. The abundant sporulation was observed in Aa2 having more than 30 spore in single microscopic field followed by
Aa1, Aa4, and Aa5 isolates which showed good sporulation having 20-30 spore in single microscopic field. Isolates Aa3 showed moderate sporulation. The present result are in agreement finding Jankar et al., (2017) who recorded variation in colony colour and soprulation among the isolates of Alternaria alternata. Result on the same line was also recorded by Rajendra et al., (2013) and Devappa and Thejakumar (2016) recorded variation in colour of aerial mycelium, growth pattern and sporulation.

\section{Size and septation of conidia of Alternaria alternata on PDA}

The result presented in table 3. Indicates distinct variation in size and septation of conidia. Among the five isolates, the maximum conidial length $(41.10 \mu \mathrm{m})$ was noticed in Aa5, followed by $(37.75 \mu \mathrm{m})$ in Aa3 while, the minimum conidial length 
$(20.30 \mu \mathrm{m})$ was noticed in Aa4 isolate. The maximum conidial breadth $(11.62 \mu \mathrm{m})$ was recorded in Aal isolate followed by $(11.52 \mu \mathrm{m})$ in Aa2. While the minimum conidial breadth $(10.20 \mu \mathrm{m})$ was noticed in Aa5 isolate. Conidial septation as presented in table 3. there was difference among the isolates with respect to tranverse and longitudinal conidial septation. The maximum number of transverse septa was observed in Aa5 (4-8) isolate and minimum (1-4) in Aa1 isolate. The maximum number of longitudinal septa was observed in Aa1 and Aa2 (0-3) and minimum in Aa5 (0-1) isolate. Overall average number of septation among the isolates varied from 1-8 transverse and 0-3 longitudinal septa. These conidial features of Alternaria alternata observed in the study are in accordance with findings of Monowara et al., (2017) who reported conidial morphological differences among the isolates of Alternaria spp. in terms of length, breadth and number of septa. Ginoya and Gohel (2015) and Jankar et al., (2017) also reported similar variation in the conidial morphology of the isolates of Alternaria alternate (Fig. 1).

\section{Pathogenicity of Alternaria alternata on host plant}

The initiation of typical symptoms appears after 5-10 days of inoculation. Formation of small necrotic lesions concentric rings on leaves, which turn brown to black in colour in advance stage they become circular to irregular in shape, was observed in (Fig. 2). The pathogen was successfully reisolated from artificially inoculated diseased plant. On comparison, reisolated culture were of identical with the pure cultures of the pathogen initially isolated from naturally infected plant which confirmed the Koch's postulates and pathogenic ability of isolated pathogen Alternaria alternata. Various earlier worker have been reported the pathogenic nature of Alternaria alternata in different crops. Kansara and sablpar (2015) proved the pathogenicity of Alternaria alternata causing leaf spot of niger. Jankar et al., (2017) and Devappa and Thejakumar (2016) were also ascertained the pathogenicity of Alternaria alternata in chilli by proving Koch's postulates.

\section{References}

Devappa, V. and M. B. Thejakumar, 2016. Morphological and physiological studies of Alternaria alternata causing leaf spot disease of Chilli (Capsicum annuum L.). Int. Jou. of App. and Pure Sci. and Agri., 2(5) ISSN: 2394-5532.

Getinet, A. and Sharma S. M., 1996. Niger (Guizotia abyssinica) promoting the conservation and use of underutilized and neglected crop. Institute Of Plant Genetics and Crop Plant Research, Gatersleben/International Plant Genetic Resources Institute, Rome, pp:1-59.

Ginoya, C. M. and N.M. Gohel, 2015. Cultural and morphological variability among the isolates of Alternaria alternata (fr.) Keissler, incitant of fruit rot of chilli. Int. J. of Plant Protection 8(1): 118-125.

Gupta, K. N. R. Bisen and A. Tiwari, 2018. A review: Current status of niger diseases and their integrated management. International Journal of Chemical Studies 6(6): 2131-2135.

Jankar K. D., E. D. Bagde and R. R. Tatte, 2017. (Thesis) Morphological and pathogenic variation of Alternaria alternata causing fruit rot of chilli.

Kansara, S. S. and A. N. Sabalpara, 2015. In vitro evaluation of botanicals against Alternaria alternata causing alternaria leaf spot of niger (Guizotia abyssinica). Trends In Biosciences 8(22).

Monowara, R., N. N. Tonu, F. begum, Md. M. karimand N. Sultana, 2017. Morphological and physiological 
variation among different isolates of Alternaria spp. from rapeseed-mustard. International Journal of Environment, Agriculture and Biotechnology (IJEAB), 2(5).

Nagaraja, O. and M. Krishnappa, 2016. Detection and Seed Transmission of Alternaria porri in Niger. Int. J. Curr. Aca. Rev. 4(10): 66-74.

Rai, S. K., D. Charak and R. Bharat, 2016. Scenaria of Oilseed Crops Across The Globe. Plant Archives 16(1):125-132.

Rajender, J. B. pushpavathi, M. Santha Lakshmi Prasad and N. Naresh, 2013.Cultural, morphological and pathogenic characterization of isolates of Alternaria helianthi causing sunflower blight. Indian Journal of Plant Protection. 41(1):76-84.

Ranganatha, ARG, A. Tripathi, A. Jyotishi, S. Paroha, M. R. Deshmukh, N. Shrivastava, 2009. Strategies to enhance the productivity of sesame, linseed and Niger. In: Proceedings of Platinum Jubilee Celebrations, UAS, Raichur.

Ranganatha, ARG. Comprehensive analysis of AICRP on Sesame and Niger. Project Coordination Unit (Sesame and Niger) ICAR, JNKVV Campus, Jabalpur, 2014, 50.

Sandipan, P. B., P. K. Jagtap and M. C. Patel, 2014. Impact of fungicide on powdery mildew and cercospora leaf spot diseases of niger (Guizotia abyssinca cass) cv under South Gujrat region. The bioscan An International Quarterly Journal of Life Science 9(3): 13231326.

Singh, A., V. Singh and S. M. Yadav, 2014. Cultural, morphological and pathogenic variability of Alternaria solani causing early blight in tomato. Plant Pathology Journal. 13 (3): 167-172.

\section{How to cite this article:}

Archana W. Shingne, Ashwini R. Bagade, Punam N. Usendi and Giri, G. K. 2020. Morphological, Cultural and Pathological Variation of Alternaria alternata causing Leaf Spot of Niger. Int.J.Curr.Microbiol.App.Sci. 9(09): 3300-3306.

doi: https://doi.org/10.20546/ijcmas.2020.909.410 